\title{
COMPARISON OF THE EFFECTIVENESS OF ROPIVACAINE SOAKED VS BUPIVACAINE SOAKED DRESSING FOR PAIN RELIEF AT SPLIT THICKNESS SKIN GRAFT DONOR SITE.
}

1. MBBS, FCPS

Assistant Professor Plastic Surgery D.G Khan Medical College.

2. MBBS, FCPS

Assistant Professor Plastic Surgery Jinnah Burn and Reconstructive Surgery Center Lahore.

3. MBBS, FCPS

Senior Registrar Plastic Surgery Jinnah Burn and Reconstructive Surgery Center Lahore.

4. MBBS, FCPS

Assistant Professor Plastic Surgery Jinnah Burn and Reconstructive Surgery Center, Lahore.

5. MBBS, FCPS Assistant Professor Plastic Surgery Holy Family Hospital Rawalpindi.

6. MBBS, FRCS, FCPS

Professor Plastic Surgery

Jinnah Burn and Reconstructive Surgery Center Lahore.

Allama Iqbal Medical College.

Correspondence Address: Dr. Abdul Malik Mujahid Department of Plastic Surgery

Burn Unit Teaching Hospital,

DG Khan Medical College DG Khan. iqbalian_127@yahoo.com

Article received on:

19/02/2020

Accepted for publication:

$02 / 04 / 2020$
Abdul Malik Mujahid', Farrukh Aslam Khalid², Kashif Mehmood Sheikh ${ }^{3}$, Muhammad Sheraz Raza ${ }^{4}$, Husnain Khan ${ }^{5}$, Moazzam Nazeer Tarar $^{6}$

ABSTRACT... Objectives: To compare the mean pain score of ropivacaine soaked dressing versus bupivacaine-soaked dressing for pain relief at the donor site among patients requiring split thickness skin grafting after burns and tissue loss. Study Design: (RCT) Randomized control trial. Setting: Department of Plastic Surgery Jinnah Burn and Reconstructive Surgery Center Lahore. Period: January 1, 2019 to June 31, 2019. Material \& Methods: Total 120 patients meeting the inclusion criteria were enrolled and divided randomly into Group-A and Group-B based on lottery method. Group A was dressed with ropivacaine soaked dressing while group-B with bupivacaine-soaked dressing. Patients were asked about pain four hours after the dressing using the verbal rating scale of 0-10. Result: Total 120 patients were included and randomly divided in to two groups. The mean age of ropivacaine group (Group A) patients was $40.82 \pm 13.20$ years and bupivacaine group (Group-B) patients was $39.70 \pm 12.20$ years. $56(46.67 \%)$ patients were males and 64(53.33\%) patients were females. Male to female ratio was $0.8: 1$. The mean size of the defect for Group-A patients was $10.43 \pm 2.92$ and Group B patients was $10.13 \pm 2.91$. The Mean Visual Rating Scale (VRS) at the baseline for ropivacaine was $7.95 \pm 1.04$ and for bupivacaine was $8.0167 \pm .791(p=0.695)$ and VRS (verbal rating scale) at 4 hours of ropivacaine group patients was $1.27 \pm 1.13$ and in bupivacaine group patients was $2.58 \pm 1.61$. The statistically significant difference is found between the two study groups for VRS at 4 hours ( $p$-value $=0.001$ ). Conclusion: Ropivacaine soaked dressing showed significantly better outcome than bupivacaine-soaked dressing at the donor site among patients requiring split thickness skin grafting after burns and tissue loss.

Key words: $\quad$ Bupivacaine, Donor Site, Ropivacaine, Soaked Dressing, Split Thickness, Skin Grafting, Verbal Rating Scale.

Article Citation: Mujahid AM, Khalid FA, Sheikh KM, Raza MS, Khan H, Tarar MN. Comparison of the effectiveness of Ropivacaine soaked vs bupivacaine soaked dressing for pain relief at split thickness skin graft donor site. Professional Med J 2020; 27(9):1952-1957. DOI: 10.29309/TPMJ/2020.27.09.4585

\section{INTRODUCTION}

Skin grafting is one of the most commonly done surgical procedure for skin and soft tissue defects (wounds). It's an important tool in reconstructive ladder and widely used by reconstructive surgeons. Split thickness skin grafts (STSG) are used in most soft tissue defects after trauma, tumor surgery and burns. STSG represent one of the most rapid and effective method of resurfacing the granulating tissue beds with large skin defects or tissue loss. In large wounds, its application is necessary to prevent contraction. It provides supple skin cover to wounds and prevent healing by secondary intention. As in secondary healing, the scar remains unstable or may convert into hypertrophic scar or keloid. ${ }^{1-3}$ As a principal, the donor site of any reconstructive procedure should heal uneventfully. Similarly, in case of STSG donor site, the aim is to provide an environment that promotes healing and prevent any complication like infection, pain and delayed healing.

Pain at the skin graft donor site can be a real problem for most patients especially in the first five postoperative days. Alleviation of this pain can achieve considerable reduction in postoperative morbidity and the fast recovery of the donor site. ${ }^{4}$ These methods include ice application at the donor site, the Fascia Iliaca compartment block, and a number of dressings. ${ }^{5}$ Bupivacaine is an anesthetic agent that blocks the nerve impulses 
that transmit pain sensation to the brain. It is most commonly used for spinal blocks but can also be used for local infiltration anesthesia and peripheral nerve blocks. ${ }^{6}$ So, bupivacaine-soaked dressing is an applicable option for split thickness skin graft donor site for early postoperative analgesia.

Special dressing with local anesthetics can be an effective and easy way to solve this problem. Studies have been conducted to assess the effectiveness of these dressings. Trost et al. reported infiltration of donor site with analgesic agent ropivacaine improves postoperative pain during 48 hours. ${ }^{7}$ Raza et al. ${ }^{6}$ reported $93.3 \%$ effectiveness of bupivacaine soaked dressing and only $4 \%$ effectiveness of conventional normal saline dressing. While Ozkiris et al. ${ }^{8}$ reported ropivacaine to be a better choice than bupivacaine due to its reduced lipophilicity which make it less toxic for cardiovascular and central nervous system. ${ }^{9}$ A study conducted by Anantanarayanam et al on the catheter based analgesia reported that ropivacaine is better than bupivacaine in pain relief with the visual analogue scale of $2.8 \pm 0.894$ and $3.7 \pm 0.875$ in two groups respectively. ${ }^{10}$

The rationale of this study is to compare the effectiveness of ropivacaine soaked vs bupivacaine-soaked dressing for pain management of the donor site of split thickness skin graft. The available local literature has shown that bupivacaine-soaked dressing is effective in management of pain but no study is available so far regarding effectiveness and safety of ropivacaine. Thus, this study would provide information regarding the role of ropivacaine in management of pain at the donor site. This would help in reduction in postoperative morbidity and quick recovery of the patients.

\section{MATERIAL \& METHODS}

This study (RCT) was done at the Plastic \& Reconstructive Surgery Department, from January 1, 2019 to June $31^{\text {st }} 2019$. The sample size of 120 patients were calculated with $95 \%$ confidence level, 5\% margin of error, $80 \%$ power of study and taking expected the mean pain score of bupivacaine-soaked dressing and $4 \%$ effectiveness of conventional dressing as
$3.7 \pm 0.875$ and of ropivacaine soaked dressing as 2.8 \pm 0.894 . After the approval from Hospital Ethical Committee and trial registration, 120 patients fulling the inclusion criteria, i.e. age 16 to 60 years, both genders and patients undergoing split thickness skin grafting after burns and tissue loss were selected through Non probability consecutive sampling. Patients with the previous allergy to anesthesia determined on history and medical record, Diabetes mellitus, Hypertension, bleeding disorders, on anticoagulant therapy and those not willing to participate in the study were excluded. An informed consent was taken from them before enrolling in the study. Patients were randomized into two groups (60 in each group) by using the lottery method by researcher. Group-A were dressed with ropivacaine soaked dressing, while the group-B with bupivacaine-soaked dressing. Dressing was soaked with $12 \mathrm{ml} / 100 \mathrm{~cm}^{2}$ of $0.25 \%$ solution of both Ropivacaine and Bupivacaine in the respective groups. ${ }^{6}$ Information regarding their demographic data was noted in the proforma. Patients were asked about pain score after four hours by consultant plastic surgeon. Confidentiality of the data was ensured. Collected data were entered and analyzed using SPSS version 17.0. Numerical variable i.e. age and pain score were summarized as mean and standard deviation. Qualitative variables like sex was presented in the form of frequency and percentages. Data was stratified for age and gender to control the effect modifier. Both groups were compared for the mean pain score of dressing and size of the defect and independent t-test was applied to check statistical significance post-stratification. The $P$ value of $<0.05$ was considered as statistically significant.

\section{RESULTS}

During the study period, a total of one hundred and twenty (120) patients were enrolled in this study. The mean age of ropivacaine group patients was $40.82 \pm 13.20$ years and bupivacaine group patients were $39.70 \pm 12.20$ years. 56(46.67\%) patients were males and 64(53.33\%) patients were females. Male to female ratio was 0.8:1. The mean size of the defect of ropivacaine group patients was $10.43 \pm 2.92$ and bupivacaine group patients were $10.13 \pm 2.91$. The statistically insignificant 
difference was found between the study groups for the size of the defect i.e. p-value $=0.574$. According to our study results the mean VRS at the baseline for ropivacaine was $7.95 \pm 1.04$ and for bupivacaine was $8.0167 \pm .791 \quad(p=0.695)$ and VRS (verbal rating scale) at 4 hours of the ropivacaine group patients was $1.27 \pm 1.13$ and in bupivacaine group patients was 2.58 \pm 1.61 . Statistically there is significant difference found between the study groups for VRS at 4 hours
( $p$-value $=0.001)$. Stratification of VRS is done for gender. In male patients, the mean VRS of the ropivacaine group patients was $1.43 \pm 1.20$ and in bupivacaine group patients was $2.82 \pm 1.39$. Similarly, in female patients, the mean VRS of the ropivacaine group patients was $1.13 \pm 1.07$ and in the bupivacaine group patients was 2.38 \pm 1.77 . The statistically significant difference was found between the study groups with VRS stratified by age, i.e. $p$-value $<0.05$.

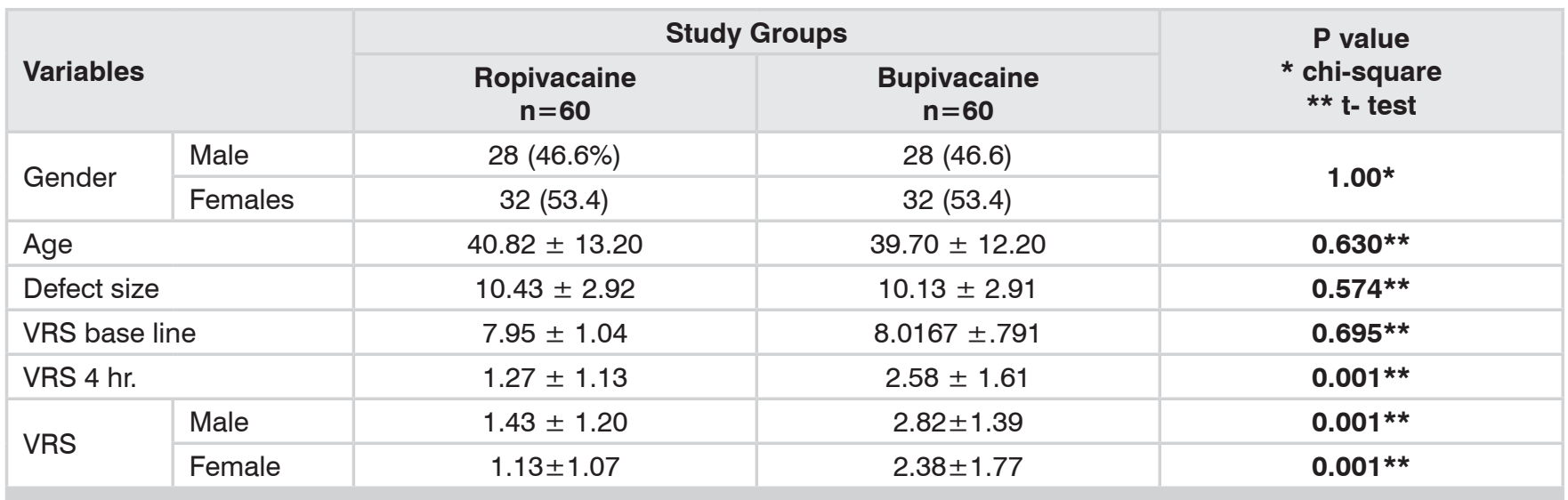

Table-I. Comparison of demographic and clinical variables among study groups

\section{DISCUSSION}

Most of skin and soft tissue defects need some form of reconstruction depending on the size and location of defects. Split thickness skin grafting (STSG) is important reconstruction tool in trauma and major burns. The simplicity of the procedure and inexpensive and readily available instrumentation has made it a very popular reconstructive option in developing and many developed countries. The donor site wound should heal completely within 7 to 21 days in ideal conditions depending on the thickness of graft. Optimum local wound care at both recipient and donor site should promote wound healing and be cost-effective, while preventing adverse effects or complications, such as discomfort, infection, pain, and scarring. ${ }^{11}$ The donor site dressing is considered as an ideal which should be easy to apply, promote rapid re-epithelialization and relatively inexpensive. ${ }^{12}$ Dressings that are more comfortable and have shorter healing time with improved skin quality after healing, would grant patients a better quality of life.

Although STSG is the standard of care for full thickness burn wounds, complications, such as impaired healing, infection, excessive pain, scarring, pruritus, and either hypopigmentation or hyperpigmentation, are common on the donor site. The donor site pain is also one of the most distressing symptoms reported by patients in the early postoperative period. ${ }^{13}$ Larger donor sites stimulate a greater number of pain receptors and consequently pain is proportional to the size of the graft harvested. Often, the donor site is reported to be more painful than the recipient site, affecting early mobilization, sleep, and need for analgesics postoperatively. Donor site pain is also a significant stressor during hospitalization and uncontrolled pain in the acute setting is a predictor of developing chronic pain in burn patients. ${ }^{14-17}$ Postoperative care for pain management after skin graft procedures usually requires multimodal therapy. Clinically significant physiological changes occur in burn patient which complicate pain management. The response to standard drugs is also altered in these patients. ${ }^{18}$

Local anesthetics as topical gel or the IV infusion have been used for pain relief in burn patients 
previously and have been found to significantly reduce pain medication consumption, without major adverse effects on wound healing. Morris and Lamb ${ }^{19}$ and Butler et al. ${ }^{20}$ assessed topical bupivacaine for donor site pain. Morris and Lamb performed a double-blind, prospective trial with 40 patients that were split into four groups. Pain was assessed via VAS on POD 1, 3, 5, and 7 and they found no significant difference in mean pain via VAS, nor in the number of days was pain felt. Butler and colleagues performed a prospective, double-blinded controlled trial with 45 patients split into three groups and pain was assessed on POD 1, 2, and 3. Pain was reported to be significantly lower on POD $1^{\text {st }}$ and $2^{\text {nd }}$ for patients receiving bupivacaine. ${ }^{13}$

In a local study by M. Raza et $a l,{ }^{6} 150$ cases who required STSG for various soft tissue defects were randomly divided into two groups. In Group A, donor site dressing was soaked with $12 \mathrm{~mL} / 100$ $\mathrm{cm} 2$ of $0.25 \%$ bupivacaine solution, and in Group $B$, dressing was soaked with the same amount of normal saline. This study results showed that Bupivacaine soaked dressing was much more effective in pain relief at split thickness skin graft donor site and reduced the requirement of rescue analgesia in the early postoperative period, compared to the conventional dressing.

Ropivacaineisfromamidegroupand islong-acting. Like other groups, the mechanism of action of ropivacaine is reversible blockage of sodium ions at nerve fibers. Other advantage of Ropivacaine is that it has greater motor sensory differentiation than bupivacaine because it is less lipophilic. This result is less motor blockade and its advantage where motor blockade is not required. This is why its less cardiotoxic than bupivacaine. Ropivacaine is also less CNS toxic than Bupivacaine. ${ }^{9}$ Its also well tolerated in pediatric patients between age group of one month to fifteen years regardless to administration route. The Gastrointestinal side effects like nausea and vomiting is less frequent with Ropivacaine use. Thus, ropivacaine, with its above-mentioned properties, is suitable option for regional anesthesia and management of postoperative and labour pain. ${ }^{21}$
In A study, Muldoon $\mathrm{T}$ et $\mathrm{al}^{22}$ reported that ropivacaine $0.2 \%$ used as epidural analgesia was not as effective as bupivacaine $0.2 \%$ for pain relief via visual analog scale scores. In another study by Trost $\mathrm{O}$ et $\mathrm{al}^{7}$, local Infiltration of skin graft donor site with ropivacaine improved postoperative pain during the first 48 hours. This is effective pain management along with a standard wound dressing.

A study in $2013^{10}$ reported that ropivacaine used as catheter-based analgesia provided excellent postoperative comfort, with earlier return to normal function compared with bupivacaine after rib graft harvesting with the significantly longer duration of action and hence, decreased the need for rescue analgesics. In controlled clinical trials a pooled analysis of data revealed, adverse events that occurred among patients who received ropivacaine via peripheral nerve block or local infiltration were headache (5\%), bradycardia (6\%), vomiting (7\%), nausea (17\%) and hypotension $(32 \%)^{23}$ In our study, the mean size of the defect of the rupivacaine group patients was $10.43 \pm 2.92$ and in bupivacaine group patients was $10.13 \pm 2.91$ i.e. $p$-value $=0.574$. In our study the mean VRS of the rupivacaine group patients was $1.27 \pm 1.13$ and in bupivacaine group patients was $2.58 \pm 1.61$. The Rupivacaine group showed statistically significant lower pain as compared to bupivacaine group i.e. $\mathrm{p}$-value $=0.001$.

\section{CONCLUSION}

It has been proved in this study that ropivacaine soaked dressing showed significantly better outcome in terms of pain relief than to bupivacainesoaked dressing at the donor site among patients requiring split thickness skin grafting after burns and tissue loss.

\section{CONFLICT OF INTEREST}

Authors have nothing to disclose.

Copyright (C 02 Apr, 2020.

\section{REFERENCES}

1. Aerden D, Bosmans I, Vanmierlo B, Spinnael J, Keymeule $B$, Van den Brande P. Skin grafting the contaminated wound bed: Reassessing the role of the preoperative swab. J Wound Care 2013; 22(2): 85-9. 
2. Blume PA, Key JJ, Thakor P, Thakor S, Sumpio B. Retrospective evaluation of clinical outcomes in subjects with split $\square$ thickness skin graft: Comparing VAC ${ }^{\circledR}$ therapy and conventional therapy in foot and ankle reconstructive surgeries. Int Wound J. 2010 ; 7(6): 480-7.

3. Donegan RJ, Schmidt BM, Blume PA. An overview of factors maximizing successful split-thickness skin grafting in diabetic wounds. Diabetic Foot Ankle 2014; 5(1): 1-11.

4. Voineskos SH, Ayeni OA, McKnight L, Thoma A. Systematic review of skin graft donor-site dressings. Plast Reconstr Surg 2009;124(1): 298-306.

5. Uygur F, Evınc R, Ulkur E, Celıkoz B. Use of lyophilized bovine collagen for split-thickness skin graft donor site management. Burns 2008; 34(7): 1011-4.

6. Raza MS, Nazim T, Khan FA. Comparison of bupivacaine moistened dressing and conventional dressing for pain relief on skin graft donor sites. $J$ Coll Physicians Surg Pak 2014; 24: 416-9.

7. Trost O, Danino A, Kadlub N, et al. Effects of local infiltration of split thickness skin grafts donor site with ropivacaine: A prospective series of $\mathbf{3 0}$ patients. Ann Chir Plast Esthet. 2005; 50(4): 309-13.

8. Özkiriş M, Kapusuz Z, Saydam L. Comparison of ropivacaine, bupivacaine and lidocaine in the management of post-tonsillectomy pain. Int $\mathrm{J}$ Pediatr Otorhinolaryngol. 2012; 76(12): 1831-4.

9. Kuthiala G, Chaudhary G. Ropivacaine: A review of its pharmacology and clinical use. Indian $\mathrm{J}$ Anaesth. 2011; 55(2): 104-10.

10. Anantanarayanan P, Raja DK, Kumar JN, Sneha P, Christabel A, Manikandhan R, et al. Catheter-based donor site analgesia after rib grafting: A prospective, randomized, double-blinded clinical trial comparing ropivacaine and bupivacaine. $\mathrm{J}$ Oral Maxillofac Surg. 2013; 71(1): 29-34.

11. Lars PKLP,Giretzlehner M, Trop M, Parvizi D, Spendel S, Schintler $\mathrm{M}$ et al. The properties of the "ideal" donor site dressing: Results of a worldwide online survey. Ann Burns Fire Disasters 2013; 26(3): 136-41.

12. Olawoye OA, Ademola SA, Iyun AO, Michael AI, Oluwatosin OM. Management of split skin graft donor site in the West African sub region: Survey of plastic surgeons' practice. Ann Burns Fire Disasters 2017; 30(2): 146-9.
13. Sinha S, Schreiner AJ, Biernaskie J, Nickerson D, Gabriel VA. Treating pain on skin graft donor sites: Review and clinical recommendations. J Trauma Acute Care Surg 2017; 83: 954-64.

14. Lowrie AG, Dabernig J, Watson SB. Operative techniques for the minimization of skin graft donorsite pain in flap surgery. Plast Reconstr Surg. 2007; 119(4): 1393-4.

15. Feldman DL, Rogers A, Karpinski RH. A prospective trial comparing Biobrane, Duoderm and xeroform for skin graft donor sites. Surg Gynecol Obstet. 1991; 173(1): 1-5.

16. Burnett LN, Carr E, Tapp D, Raffin Bouchal S, Horch JD, Biernaskie J, et al. Patient experiences living with split thickness skin grafts. Burns. 2014; 40(6): 1097-105.

17. Wiechula $R$. The use of moist wound-healing dressings in the management of split-thickness skin graft donor sites: A systematic review. Int J Nurs Pract. 2003; 9(2): S9-S17.

18. Sharmila Dissanaike, Jayne McCauley, Carlo Alphonso Liposomal bupivacaine for the management of postsurgical donor site pain in patients with burn injuries: A case series from two institutions. Clin Case Rep 2018; 6(1): 129-35.

19. Morris WT, Lamb AM. Painless split skin donor sites: A controlled doubleblind trial of Opsite, scarlet red and bupivacaine. Aust N Z J Surg 1990; 60(8): 617-20.

20. Butler PE, Eadie PA, Lawlor D, Edwards G, McHugh M. Bupivacaine and Kaltostat reduces post-operative donor site pain. Br J Plast Surg 1993; 46(6): 523-4.

21. Bosenberg A, Thomas J, Lopez T, Lybeck A, Huizar $K$, Larsson LE. The efficacy of caudal ropivacaine 1,2 and $3 \mathrm{mg} / \mathrm{ml}$ for postoperative analgesia in children. Paediatr Anaesth 2002; 12: 53-8.

22. Muldoon T, Milligan K, Quinn P, Connolly D, Nilsson K. Comparison between extradural infusion of ropivacaine or bupivacaine for the prevention of postoperative pain after total knee arthroplasty. $\mathrm{Br} \mathrm{J}$ Anaesth 1998; 80(5):680-1.

23. Simpson D, Curran MP, Oldfield V, Keating GM. Ropivacaine. Drugs 2005; 65(18): 2675-717. 


\begin{tabular}{|c|c|c|c|}
\hline \multicolumn{3}{|c}{ AUTHORSHIP AND CONTRIBUTION DECLARATION } \\
\hline Sr. \# & Author(s) Full Name & \multicolumn{1}{|c|}{ Contribution to the paper } & Author(s) Signature \\
\hline 1 & Abdul Malik Mujahid & $\begin{array}{l}\text { Principal contributor, } \\
\text { conceptualization and design } \\
\text { of research work, data } \\
\text { collection. } \\
\text { Data collection, statistical } \\
\text { analysis, interpretation of data. } \\
\text { Writing of manuscript, resutls, } \\
\text { analysis. } \\
\text { Drafting, literature search, data } \\
\text { collection, final review. } \\
\text { Literature search, statistical } \\
\text { analysis, revision of } \\
\text { manuscript. } \\
\text { Drafting, review of resutls and } \\
\text { final approval. }\end{array}$ \\
\hline Kashif Mehmood Sheikh & M. Sheraz Raza & Moazzam Nazeer Tarar & \\
\hline
\end{tabular}

